The middle and latter thirds of the book comprise a detailed dictionary, occupying another 650 pages, of analytical data from Acepifylline to Yohimbine, with MP and Rf values, u-v maxima, i-v peaks and characteristic spectra, reagent data-and a very full bibliography. It is a remarkable book: a vade mecum every analytical chemist and toxicologist must have at his elbow. It is, indeed, the only really full and authoritative guide in this difficult field, of equal importance to both clinical and postmortem toxicologists. The price is immaterial.

KEITH SIMPSON

Diagnostic Uses of Radioisotopes in Medicine Edited by P. A. Anderson (Pp. 1040; illustrated. 15s.) London: Hospital Medical Publications Ltd. 1969.

The journal Hospital Medicine is by now a familiar source of general information. This is the first book in a series presenting contributions, brought up to date where necessary, already published in the journal by authors well known in their various fields. An introductory article (H.I. Glass) sets the isotopic scene. Other chapters cover thyroid disorders (A. W. G. Goolden), brain disorders (W. B. Jennett), haematology (S. M. Lewis and L. Szur), body composition studies (E. S. Williams), calcium metabolism (B. E. C. Nordin), gastroenterology (D. N. Croft), blood flow (N. Veall), renal function (A. M. Joekes), and skeletal scintigraphy (V. R. McCready).

The authors succeed admirably within the scope of 100 pages in conveying the essentials of their subjects, and the book is recommended to those wishing to improve their general knowledge of diagnostic techniques using radioisotopes.

C. B. CAMERON

\section{Laboratory Aids in Diagnosis of Cancer}

By Cornelia Hoch-Ligeti. $(x+123$. \$9.50.) Springfield, Illinois. Charles C. Thomas. 1969.

It is tempting to condemn this book on the Editor's foreword alone: 'Cancer is a striking process of cell anarchy distinguished by autonomy and anaplasia with total disregard for normal limitations of growth, and complete loss of normal organisation and function. The malignant cells brutally ride roughshod...', but that might be unfair on the author who seems to have a more realistic view of neoplasia. Certainly her aim 'to review the main trends from 1955 to 1968 in ancillary diagnosis of cancer' is a good one and her conclusions are never too dogmatic.

The content includes chromosome analysis, various aspects of chemistry, immunology, and histology; a brief mention of lymphography, mammography, and thermography; and a very selective glance at isotope scanning.

Sixty-eight pages allow only a very condensed account of any technique (why then waste a page on ABO blood groups?) but full references to review articles are some compensation for lack of detail. In some sections the information is already out of date, eg, the significance of the Australia antigen, and Astaldi's revised data on PHA-responsiveness in chronic lymphatic leukaemia. Chromosome changes in acute leukaemia are scarcely mentioned and the production of lysozyme by the cells of monocytic leukaemia is omitted. In other sections a critical value judgement would have been welcome. For example, should one have to pay any attention to the Rand 3-D test? And what certain conclusions can be drawn from the mass of work on circulating malignant cells?

With these reservations the book has some value in indicating what has happened in the field of cancer diagnosis and where to find out about it.

H. E. M. KAY

Handbook of Plastic Embedding By E. L. Lutz, Snr. (Pp. v + 192; illustrated. Hardback, \$5.95; paperback, \$3.95) Healdsburg, California: Naturegraph Publications. 1969.

The art of resin embedding is a fascinating one which yields tremendous scope for the hobbyist and commercial producer alike. Such persons and others have long awaited a comprehensive handbook on the various methods and problems of plastic embedding for all types of objects-animals and plants included. Drawing upon a life time of experience and practise the author has produced a monograph of invaluable information.

Regrettably the text suffers by being both dulland, at times, padded; the photographic illustrations are poor and the diagrams suffer considerably from poor layout and quality of reproduction, those on page 151 (paperback) being the classic example.

The discerning reader, however, taking his time, will find a vast amount of useful information, although as the 192-page paperback costs $33 s$, he may not always feel that he is getting value for money. A more carefully prepared second edition is obviously justified.

IAN HUNTER
Letter to the Editor

\section{Reconditioned Laboratory Equipment}

Since November 1966, 400 consignmen $\vec{B}$ of reconditioned medical and surgicat equipment and hospital sundries has been shipped to the developing countries. by the Joint Mission Hospital Equipment Board.

This Organization, sponsored by rejw resentative British missionary societie and charitable organizations, is recog nized officially as an avenue of disposaी for redundant hospital equipment. The Board is non-profit making but has to pass on its operative costs.

Requests for laboratory equipment are now becoming more numerous as. medicine overseas develops from if earlier somewhat primitive beginning.

This development coincides with the growing sophistication of equipment use $\$$ in hospital and other laboratories of the $\mathrm{UK}$, and the consequent freeing of simple? equipment which once seemed adequateo

The more sophisticated equipmen would often be unsuited to the require $\Rightarrow$ ments of a hospital where means of controlling ambient temperature and humidity are not available, but man laboratories have equpiment which the no longer use, stored in cupboards of on shelves. This equipment would give years of useful service in mission and other charitable hospitals overseas.

If your readers have such equipment $\frac{\delta}{2}$ the J.M.H.E.B. would be glad to receive it and service it as necessary before despatching it. R. W. Bovañ
Joint Mission Hospital Equipment Board
124 Spa Road, Bermondsey?
London, SE I6त

Notice

\section{Royal College of Pathology}

The College moved into its new premises? at 2 Carlton House Terrace, London, SW1 on 12 May. 